\title{
Can surgery provoke the outgrowth of latent breast cancer? A unifying hypothesis
}

\author{
M. W. Retskyª, R. Demicheli ${ }^{\text {b }}$ W. J. M. Hrusheskyc, M. Baumd, I. D. Gukas ${ }^{e}$ \\ ${ }^{a}$ Department of Vascular Biology, Children's Hospital and Harvard Medical School, Boston, MA, USA; \\ ${ }^{b}$ Department of Medical Oncology, Istituto Nazionale Tumori, Milano, Italy; ${ }^{c}$ The University of South Carolina, \\ Dorn VA Medical Center, Columbia, SC, USA; ' University College, London; ${ }^{e}$ School of Medicine, \\ Health Policy and Practice, University of East Anglia, Norwich, UK.
}

\begin{abstract}
To explain bimodal relapse patterns, we have previously suggested that metastatic breast cancer growth commonly includes periods of temporary dormancy at both the single cell and avascular micrometastasis phases (with 1 year and 2 year half-lives respectively). We further suggested that primary surgery sometimes initiates growth of distant dormant disease accelerating relapse. These iatrogenic events are common in that they occur in over half of all relapses. Surgery induced angiogenesis is mostly confined to premenopausal node positive patients in which case $20 \%$ of patients are so affected. We review here how this hypothesis explains a vairety of previously unrelated breast cancer phenomenon including 1) the mammography paradox for women age 40-49 untreated with adjuvant therapy, 2) the particularly high benefit of adjuvant chemotherapy for premenopausal node positive patients, 3) the heterogeneity of breast cancer, 4) the aggressiveness of cancer in young women, 5) the outcome differences with timing of surgery within the menstrual cycle, 6) the common myths regarding cancer spreading "when the air hits it" and treatment "provoking" the tumor, 7) the excess mortality of blacks over whites, and 8) reports from physicians 2000 years ago. In parallel to physicists who have long sought to explain all of physics with a unified field theory, we now suggest temporary dormancy together with surgery induced tumor growth provides a unifying theory for much of breat cancer.
\end{abstract}

Keywords: Adjuvant chemotherapy, Aggressiveness, Bimodal relapse pattern, Mammography paradox, Racial differences in outcome, Surgery-induced angiogenesis, Surgery-induced tumor growth, Temporary dormancy

\section{Introduction}

Ten years ago, we were confronted with data in two separate databases from different countries [1,2] demonstrating a bimodal relapse pattern among early stage breast cancer patients untreated with adjuvant therapy. This pattern has since been

Correspondence to: Michael W. Retsky, PhD, Department of Vascular Biology, Children's Hospital and Harvard Medical School, 300 Longwood Avenue, Boston, MA 02115, USA. Email: michael.retsky@childrens.harvard.edu; Tel/fax: +203452 1649

Received: 05/02/2007

Accepted: 14/05/2007

$\mathrm{BCO} / 511 / 2006 / \mathrm{FO}$ confirmed, extended to mortality and broadened to include patients given adjuvant chemotherapy [3-7]. This biomodality is also adumbrated by other studies [8-16]. Data from Milan that we studied extensively clearly demonstrate a dominant early sharp peak at 18 months, a nadir at 50 months and second broad peak at 60 months that extends for at least 15 years. This was not predicted by any prevailing theory of breast cancer biology. It strongly implied that there was more than one mode of treatment failure.

Accordingly, we took a fresh look at how metastatic tumors grow. We proposed a growth model $[17,18]$ focusing upon the putative existence of three distinct phases - the single malignant cell, an avascular 
group of cells and a vascularized lesion. We allowed but did not insist that dormancy could exist at the single cell level and also at the point prior to tumor angiogenesis. Simulation of growth through these three stages predicted the second peak as a steady stochastic progression from one phase to the next with dormant half-life of a single cell of 1 year and dormant half-life of an avascular micrometastasis of 2 years. In order to simulate the first peak, however, we needed to postulate a uniform exciting event that stimulates state transitions. We postulated that surgical resection of the primary tumor provides this stimulus. To explain the very earliest relapse events (i.e. within 10 months of surgery), we proposed that $20 \%$ of premenopausal patients with positive lymph nodes underwent surgery-induced angiogenesis. Here, we briefly describe how this hypothesis may reasonably explain other outcome differences.

\section{A single hypothesis may help explain a variety of previously unconnected breast cancer effects (Fig. 1)}

\section{Mammography paradox for women age 40-49}

Seven important randomized controlled trials of early detection using mammography were conducted before widespread use of adjuvant chemotherapy began in approximately 1980 [19-22]. For women age 50-59 each study demonstrated a clear and early $20-30 \%$ mortality advantage resulting from screening mediated early detection of breast cancer. However, for women age 40-49, there was an early disadvantage in the first 6-8 years after screening started. Afterwards, the expected advantage appeared among all trials and overviews. Due to these unexpected results, the trials have been carefully scrutinized and a number of potential flaws have been uncovered.

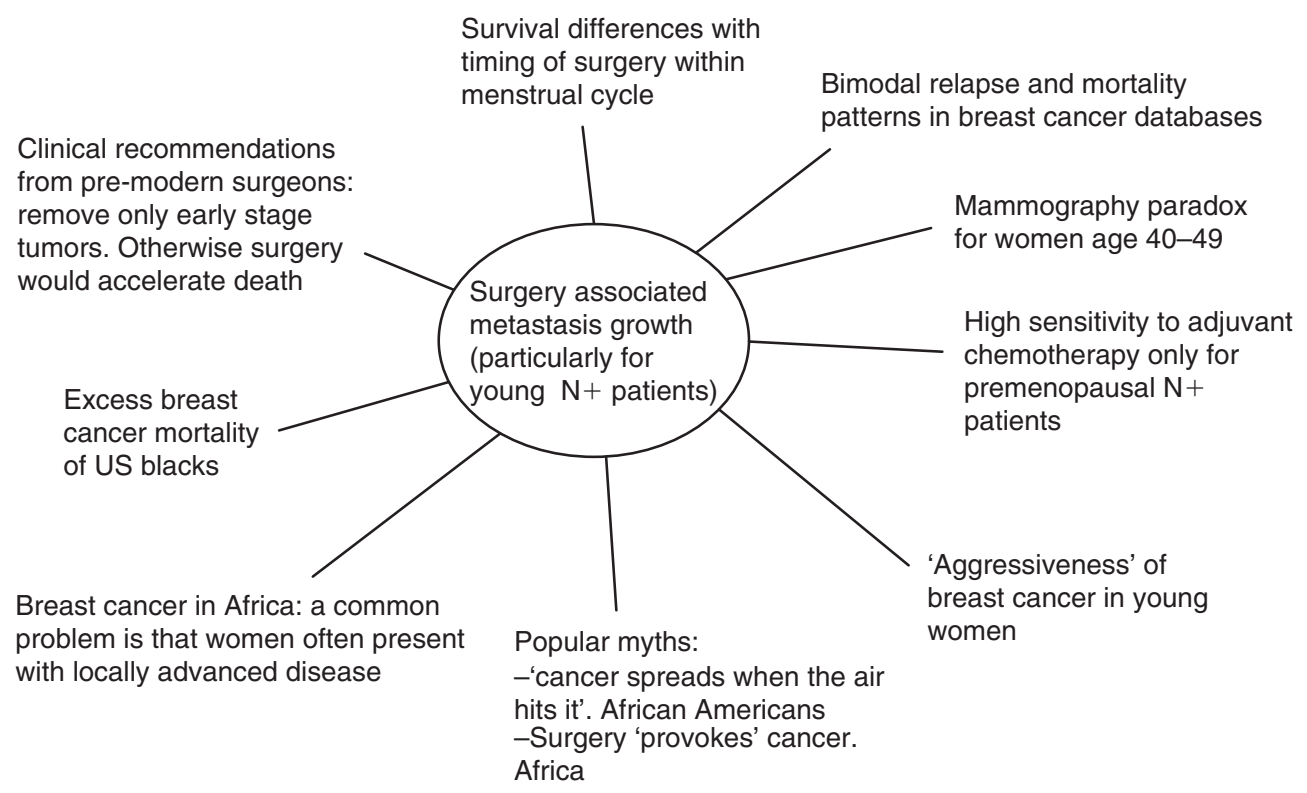

Fig. 1. Surgery may kick-start growth of dormant micrometastases in breast cancer-particularly to induce angiogenesis in approximately $20 \%$ of premenopausal node positive patients. This single hypothesis seems to explain a variety of previously unconnected effects in breast cancer.

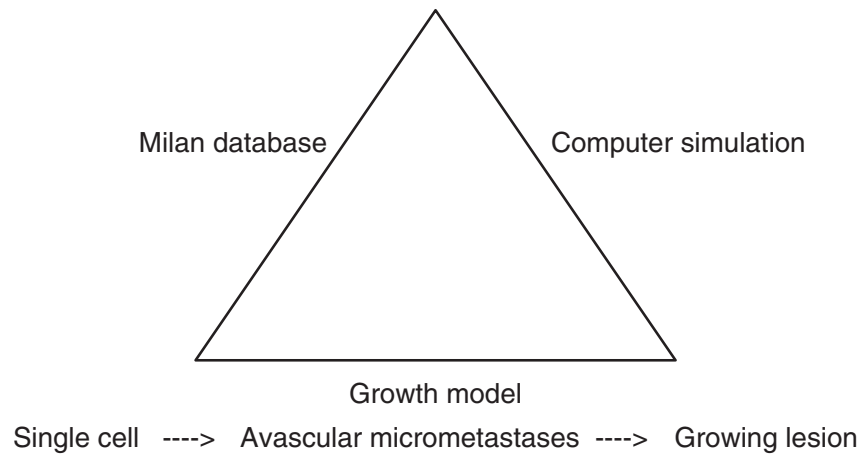

(Possible dormancy)

(Possible dormancy) 
There was a strong tendency of the mammography screening community to dismiss these data. However, early transient mortality excess of invited women, documented consistently across screening trials, countries, and time, in our opinion makes this worthy of careful consideration.

We observed that screening and control arms, otherwise similar due to randomization, have different surgery timing distributions which result directly from the early recruitment of breast cancer diagnoses in the screening arm only. We calculated that surgery induced angiogenesis, as determined by the Milan data, accelerates breast cancer mortality by approximately 2 years, causing 0.1 early deaths per 1000 screened young women in the 2nd or 3rd year after starting screening. Both the magnitude and timing agree with findings from individual trials and overviews [23-25].

\section{Heterogeneity of breast cancer - Aggressiveness of breast cancer in young women}

Breast cancer exhibits extreme variability in outcome for patients within seemingly single prognostic categories. Our theory suggests that the course of breast cancer may be characterized by a common pathway through sequential dormant and active states eventually resulting in clustered appearances of clinical metastases from a common inciting event. The balance between tumor and host influences the pace of traverse through this common pathway. Therefore, the recurrence risk profile of a single patient is determined by a specific mix of prognostic factors, resulting from the unique genetic, environmental or behavioral peculiarities of that individual as well as the timing of that inciting event. Thus, the model provides some explanation for very early, intermediate, and very late relapses. As an example, this framework may help us to better understand the well-accepted observation that breast cancer in young women is often 'aggressive'. From our perspective, this term well fits the $20 \%$ of premenopausal node-positive patients that relapse within 1 year of surgery as a result of surgery-induced angiogenesis.

\section{Highest sensitivity to adjuvant chemotherapy for premenopausal node-positive patients - Benefit even of a short course adjuvant chemotherapy immediately postoperative}

Following early adjuvant chemotherapy trials, consensus reports (1980 and 1985 National Institutes of Health Consensus Development Conferences) recommended using adjuvant chemotherapy for premenopausal node-positive patients, where the treatment proved to be quite effective. Only in later years, after careful analysis of much larger trials with longer follow-up, was it determined that adjuvant chemotherapy is of some value in other subsets of patients. Our model provides a reasonable explanation why adjuvant chemotherapy works particularly well for certain patient categories [26].

As we have previously stated, removal of the primary tumor stimulates angiogenesis in distant dormant micrometastases in a substantial fraction of premenopausal node-positive patients. This sudden release from dormancy, in synchrony with surgery, ushers in rapid growth of micrometastases and corresponding high chemosensitivity just at the time when adjuvant chemotherapy was empirically determined to be most effective.

The model, in particular, helps us better understand past reports of Scandinavian randomized clinical trials employing a single course of perioperative Cyclophosphamide. When the drug was given i.v. for 6 days immediately after mastectomy, the relapsefree rates were significantly increased, and after 20 years the difference was $13.5 \%$ [27]. When the same adjuvant course was given 2-4 weeks after mastectomy [28], there was no benefit. Further attempts to repeat this finding resulted in conflicting results [29-31] likely because of the modest effectiveness of the treatment that may be easily obscured by patient traits heterogeneity.

An overview of randomized trials indicates that perioperative chemotherapy may prolong diseasefree survival in some subsets of patients [32]. We suggest that the modest cytotoxic effect of perioperative systemic treatment may be observed because surgery-induced angiogenesis results in high proliferation rate, growth fraction of micrometastases, tumors are small in size and dividing cells are exposed to drugs via newly existing vasculature. This most highly sensitive window to antiproliferative cytotoxic agents may be open only briefly.

\section{Survival differences with timing of surgery within the menstrual cycle}

The observation that primary breast cancer surgery during the luteal phase of the menstrual cycle may improve survival of patients compared to surgery during the follicular phase was reported more than 15 years ago [33]. Since then the subject, that is intrinsically difficult due to the difficulty to confidently establish the timing of surgery relative to menstrual cycle, has been addressed in a number of reports confirming and sometimes not confirming the finding $[34,35]$. Our model provides a biological basis for understanding this phenomenon. Angiogenesis in breast tissue is modulated by the sex hormones of 
the menstrual cycle. Further, prognostic factors such as histological grade and hormone receptor concentration proved to have different age distribution and age-specific incidence rate patterns, with typical changes at the age of menopause [36], and change rhythmically in breast cancer cells during each menstrual cycle $[37,38]$. Indeed, sex hormone levels, that modulate angiogenesis in normal female reproductive tissues, mainly via effects on endothelial cells [39], also participate in the regulation of angiogenesis in breast tissue and breast cancers. VEGF waxes and wanes in normal breast tissue within each menstrual cycle [40]. Estrogens have been shown to regulate the bioactive fraction VEGF in normal human breast tissue in vivo [41], and to drive pro-angiogenic effects in animal models $[42,43]$.

Other findings support the subtle and rapid rhythmic changes in the sensitivity of tumor cells to environmental factors. The circadian clock within cancer cells apparently coordinates cancer growth rate [43]. The mechanisms of this intermittent cancer growth include circadian clock coordination of VEGF induced capillary permeability and blood flow [44]. The estrogen/progesterone ratio apparently regulates cancer cell VEGF and bFGF, and cancer growth rate and metastatic potential [45].

\section{Excess breast cancer mortality for African-American women}

There is an excess mortality in breast cancer of African-American (AA) women compared to EuropeanAmerican (EA) women that first appeared in 1970s and has been worsening since [46]. The racial disparity seems to be partly related to the introduction of mammography screening [47], although it is not fully explainable based upon a two-tiered access to medical care [48].

This explanation of the racial disparity is supported by our metastatic model. The average age of breast cancer diagnosis among AA women is 46 while it is 57 for EA women [47]. Thus, since mammography is more beneficial for postmenopausal women than it is for premenopausal women (see mammography paradox above), and may set in motion a chain of events among premenopausal women that result in early post-resection recurrence, it should be expected that after the introduction of mammography in the 1970s, mortality advantages to EA over AA should appear.

Other racial biologic differences may also play a role in these outcome disparities. Indeed, premenopausal sex cycle hormone concentrations and menstrual cycle differences that exist between $A A$ and EA might also help explain racial outcome differences. In fact, luteal phase estradiol levels are higher in $A A$ than in EA [49,50]. African-American women undergo menarche earlier than EA [51] and also tend to cycle more rapidly than their Caucasian counterparts [52]. Each of these differences in the cycle and its sex hormones could contribute to racial outcome differences.

\section{Clinical recommendations from pre-modern surgeons and popular myths}

Our model, supported by ample data from animal models, assumes that surgery may accelerate the metastasis development. Thousands of years ago, surgeons, including Celsus ( $30 \mathrm{BC}$ to $38 \mathrm{AD}$ ) and Galen (131 AD to $203 \mathrm{AD}$ ), believed that favorable results could occasionally be achieved by removal of small easily resectable lumps, while surgery was always detrimental quoad vitam and quoad valetudinem for more advanced cases [53]. As Celsus noted: 'First there is the cacoetheses, then carcinoma without ulceration, then the fungating ulcer ... None of these can be removed but the cacoetheses; the rest are irritated by every method of cure. The more violent the operations the more angry they grow'. It seems that we are not the first to recognize that surgery to remove a primary breast tumor can accelerate distant relapse. Apparently we rediscovered something that was known to surgeons 2000 years ago.

Moreover, it is noteworthy that the notion of surgery-driven acceleration of the disease course is in agreement with popular 'myths' frequently dismissed by the medical community as superstitious fables. 'Cancer spreads when the air hits it' (or words to that effect) is a common popular myth in the United States. It is believed by $61 \%$ of $A A$ and $29 \%$ of EA [54]. It is considered to be a major reason for reluctance of minorities to participate in early detection protocols. Breast surgeons practicing in Africa, where the prognosis of breast cancer is particularly poor $[55,56]$ report that very often patients have the firm belief that surgery 'provokes' the tumor to spread, and, as a result, turn to physicians with locally advanced disease after pursuing alternative therapy.

\section{Conclusions}

Breast cancer biology and outcome are characterized by a long list of seemingly unrelated effects, some of which we describe above. Our studies lead us to propose that these are not separate but intimately linked as manifestations of a single simple hypothesis. The parable of the elephant and the blind men comes to mind. To us, it is refreshing that the same biology that governs the benefit of early detection of breast cancer seems to also influence the utility of adjuvant chemotherapy. 
It is easy to disprove a theory when it does not agree with observations but it is impossible to prove a theory since there are always new tests to which it that can and should be subjected. A theory gradually becomes accepted over time when it continues to successfully explain new data and predictions. This process cannot be rushed since it necessarily involves extensive independent testing and verification.

In a manner, we are mimicking physicists who have attempted for many decades to explain wide ranging interactions between objects including stars and nucleons by describing fundamental forces responsible for those interactions with one unifying theory.

While there may not be a unified theory for all of physics, there as well may not be a unified theory of breast cancer. We believe, however, that the framework that we propose does provide a parsimonious explanation for many apparently unrelated breast cancer behaviors. We welcome attempts to challenge this theory since challenge is essential to advance theoretical understanding that will eventually lead to the truth which will, in turn, improve patient outcome.

\section{References}

1. Demicheli R, Abbattista A, Miceli R, Valagussa $P$, Bonadonna $\mathrm{G}$. Time distribution of the recurrence risk for breast cancer patients undergoing mastectomy: further support about the concept of tumour dormancy. Breast Cancer Res Treat 1996; 41: 177-185.

2. Baum M, Chaplain MA, Anderson AR, Douek M, Vaidya JS. Does breast cancer exist in a state of chaos? Eur $J$ Cancer 1999; 35: 886-891.

3. Gasparini G, Biganzoli E, Bonoldi E, Morabito A, Fanelli M, Boracchi P. Angiogenesis sustains tumor dormancy in patients with breast cancer treated with adjuvant chemotherapy. Breast Cancer Res Treat 2001; 65(1): 71-75.

4. Jatoi I, Tsimelzon A, Weiss H, Clark GM, Hilsenbeck SG. Hazard rates of recurrence following diagnosis of primary breast cancer. Breast Cancer Res Treat 2005; 89: 173-178.

5. Jerez JM, Franci L, Alba E, Llombart-Cussiac A, Lluch A, Ribelles N, Munarriz B, Martin M. Improvements of breast cancer prediction in high risk intervals using artificial neural networks. Breast Cancer Res Treat 2005; 94: 265-272.

6. Demicheli R, Miceli R, Moliterni A, Zambetti M, Hrushesky WJ, Retsky MW, Valagussa P, Bonadonna G. Breast cancer recurrence dynamics following adjuvant $\mathrm{CMF}$ is consistent with tumour dormancy and mastectomydriven acceleration of the metastatic process. Ann Oncol 2005; 16: 1449-1457.

7. Demicheli R, Bonadonna G, Hrushesky WJM, Retsky MW, Valagussa P. Menopausal status dependence of the early mortality reduction due to diagnosing smaller breast cancers (T1 versus T2-T3): relevance to screening. J Clin Oncol 2004; 22(1): 102-107.

8. Fisher B, Anderson S, Fisher ER, Redmond C, Wickerham DL, Wolmark N, Mamounas EP, Deutsch M, Margolese R. Significance of ipsilateral breast tumour recurrence after lumpectomy. Lancet 1991; 338: 327-331.

9. De la Rochefordiere A, Asselain B, Campana F, Scholl SM, Fenton J, Vilcoq JR, Durand JC, Pouillart P, Magdelenat H,
Fourquet A. Age as prognostic factor in premenopausal breast carcinoma. Lancet 1993; 341: 1039-1043.

10. Veronesi U, Marubini E, Del Vecchio M, Manzari A, Andreola S, Greco M, Luini A, Merson M, Saccozzi R, Rilke F, et al. Local recurrences and distant metastases after conservative breast cancer treatments: partly independent events. J Natl Cancer Inst 1995; 87: 19-27.

11. Saphner T, Tormey DC, Gray R. Annual hazard rates of recurrence for breast cancer after primary therapy. J Clin Oncol 1996; 14: 2738-2746.

12. Hilsenbeck SG, Ravdin PM, de Moor CA, Chamness GC, Osborne CK, Clark GM. Time-dependence of hazard ratios for prognostic factors in primary breast cancer. Breast Cancer Res Treat 1998; 52: 227-237.

13. Karrison TG, Ferguson DJ, Meier P. Dormancy of mammary carcinoma after mastectomy. $J$ Natl Cancer Inst 1999; 91: 80-85.

14. Fortin A, Larochelle M, Laverdiere J, Lavertu S, Tremblay D. Local failure is responsible for the decrease in survival for patients with breast cancer treated with conservative surgery and postoperative radiotherapy. J Clin Oncol 1999; 17: 101-109.

15. Yakovlev AJ, Tsodikov AD, Boucher K, Kerber R. The shape of the hazard function in breast carcinoma. Cancer 1999; 85: 1789-1798.

16. Sant M, Gatta G, Micheli A, Verdecchia A, Capocaccia R, Crosignani P, Berrino F. Survival and age at diagnosis of breast cancer in a population-based cancer registry. Eur J Cancer 1991; 27(8): 981-984.

17. Demicheli R, Retsky MW, Swartzendruber DE, Bonadonna G. Proposal for a new model of breast cancer metastatic development. Ann Oncol 1997; 8: 1075-1080.

18. Retsky MW, Demicheli R, Swartzendruber DE, Bame PD, Wardwell RH, Bonadonna G, Speer JF, Valagussa P. Computer simulation of a breast cancer metastasis model. Breast Cancer Res Treat 1997; 45: 193-202.

19. Shapiro S. Periodic screening for breast cancer. The HIP Randomized Controlled Trial. Health Insurance Plan. J Natl Cancer Inst Monogr 1997; 22: 27-30.

20. Miller AB, To T, Baines CJ, Walls C. The Canadian National Breast Screening Study: update on breast cancer mortality. J Natl Cancer Inst Monogr 1997; 22: 37-41.

21. Alexander FE, Anderson TJ, Brown HK, Forrest AP, Hepburn W, Kirkpatrik AE, Muir BB, Prescott RJ, Smith A. 14 years of follow-up from the Edimburgh randomised trial of breast cancer screening. Lancet 1999; 353: 1903-1908.

22. Nystrom L, Andersson, Bjustram N, Frisell J, Nordenskjold B, Rutqvist LE. Long-term effects of mammography screening: updated overview of the Swedish randomised trials. Lancet 2002; 359: 909-919.

23. Retsky M, Demicheli R, Hrushesky W. Premenopausal status accelerates relapse in node positive breast cancer: hypothesis links angiogenesis, screening controversy. Breast Cancer Res Treat 2001; 65: 217-224.

24. Retsky M, Demicheli R, Hrushesky W. Breast cancer screening: controversies and future directions. Curr Opin Obstetr Gynecol 2003; 15: 1-8.

25. Retsky M, Demicheli R, Hrushesky WJM. Does surgery induce angiogenesis in breast cancer? Indirect evidence from relapse pattern and mammography paradox. Int $J$ Surg 2005; 3(3): 179-187.

26. Retsky M, Bonadonna G, Demicheli R, Folkman J, Hrushesky W, Valagussa P. Hypothesis: induced angiogenesis after surgery in premenopausal node-positive 
breast cancer patients is a major underlying reason why adjuvant chemotherapy works particularly well for those patients. Breast Cancer Res 2004; 6: R372-R374.

27. Kjellgren K, Nissen-Meyer R, Norin T. Perioperative adjuvant chemotherapy in breast cancer. The Scandinavian Adjuvant Chemotherapy Study 1. Acta Oncol 1989; 28: 899-901.

28. Nissen-Meyer R, Host H, Kjellgren K, Mansson B, Norin T. Short perioperative versus long-term adjuvant chemotherapy. Recent Results Cancer Res 1985; 98: 91-98.

29. Baum M, Houghton J, Riley D. On behalf of the Cancer Research Campaign Breast Cancer Trials Group. Results of the Cancer Research Campaign adjuvant trial for perioperative cyclophosphamide and long-term tamoxifen in early breast cancer reported at the tenth year of follow-up. Acta Oncologica 1992; 31: 251-257.

30. Colleoni M, Gelber S, Coates AS, Castiglione-Gertsch M, Gelber RD, Price K, Rudenstam CM, Lindtner J, Collins J, Thurlimann B, Holmberg SB, Cortes-Funes H, Simoncini E, Murray E, Fey M, Goldhirsch A. International Breast Cancer Study Group. Influence of endocrine-related factors on response to perioperative chemotherapy for patients with node-negative breast cancer. $J$ Clin Oncol 2001; 19(21): 4141-4149.

31. Sertoli MR, Bruzzi P, Pronzato P, Queirolo P, Amoroso D, Del Mastro L, Venturini M, Vigani A, Bertelli G, Campora E, et al. Randomized cooperative study of perioperative chemotherapy in breast cancer. J Clin Oncol 1995; 13(11): 2712-2721.

32. Clahsen PC, van de Velde CJ, Goldhirsch A, Rossbach J, Sertoli MR, Bijnens L, Sylvester RJ. Overview of randomized perioperative polychemotherapy trials in women with earlystage breast cancer. J Clin Oncol 1997; 15(7): 2526-2535.

33. Hrushesky WJM, Bluming AZ, Gruber SA, Sothern RB. Menstrual influence on surgical cure of breast cancer. Lancet 1989; 338: 949-952.

34. Badwe RA, Mittra I, Havaldar R. Timing of surgery during the menstrual cycle and prognosis of breast cancer. $J$ Biosci 2000; 25: 113-120.

35. Chaudhry A, Puntis ML, Gikas P, Mokbel K. Does the timing of breast cancer surgery in pre-menopausal women affect clinical outcome? An update. Int Semin Surg Oncol 2006; 3: 37.

36. Anderson WF, Jatoi I, Devesa SS. Distinct breast cancer incidence and prognostic patterns in the NCl's SEER program: suggesting a possible link between aetiology and outcome. Breast Cancer Res Treat 2005; 90: 127-137.

37. Pujol P, Daures JP, Thezenas S, Guilleux F, Rouanet P, Grenier J. Changing estrogen and progesterone receptor pattern in breast carcinoma during menstrual cycle and menopause. Cancer 1998; 83: 698-705.

38. Coradini D, Veneroni S, Pellizzaro C, Daidone MG. Fluctuation of intratumour biological variables as a function of menstrual timing of surgery for breast cancer in premenopausal patients. Ann Oncol 2003; 14: 962-964.

39. Losordo DW, Isner JM, Estrogen and angiogenesis: a review. Arterioscler Thromb Vasc Biol 2001; 21: 6-12.

40. Dabrosin C. Variability of vascular endothelial growth factor in normal human breast tissue in vivo during the menstrual cycle. J Clin Endocrinol Metab 2003; 88: 2695-2698.
41. Dabrosin C. Positive correlation between estradiol and vascular endothelial growth factor but not fibroblast growth factor-2 in normal breast tissue in vivo. Clin Cancer Res 2005; 11: 8036-8041.

42. Dabrosin C. Sex steroid regulation of angiogenesis in breast tissue. Angiogenesis 2005; 8(2): 127-136.

43. Wood PA, Bove K, You S, Chambers A, Hrushesky W. Cancer Growth and Spread are Saltatory and PhaseLocked to the Reproductive Cycle Through Mediators of Angiogenesis. Mol Cancer Ther 2005; 4(7): 1065-1075.

44. Wood PA, You S, Du-Quiton J, Hrushesky WJM. Circadian clock coordinates cancer cell cycle progression, Thymidylate Synthase (TS), and 5-Fluorouracil (5-FU) Therapeutic Index. Mol Cancer Ther 2006; 5(8): 2023-2033.

45. Bove K, Lincoln DW, Wood PA, Hrushesky WJ. Fertility cycle influence on surgical breast cancer cure. Breast Cancer Res Treat 2002; 75(1): 65-72.

46. Brawley OW. Disaggregating the effects of race and poverty on breast cancer outcomes. J Natl Cancer Inst 2002; 94: 471-473.

47. Jatoi I, Anderson WF, Rao SR, Devesa SS. Breast cancer trends among black and white women in the United States. J Clin Oncol 2005; 23: 7836-7841.

48. Jatoi I, Becher H, Leake CR. Widening disparity in survival between white and African-American patients with breast carcinoma treated in the US Department of Defense Healthcare system. Cancer 2003; 98: 894-899.

49. Manson JM, Sammel MD, Freeman EW, Grisso JA. Racial differences in sex hormone levels in women approaching the transition to menopause. Fertil Steril 2001; 75: 297-304.

50. Pinheiro SP, Holmes MD, Pollak MN, Barbieri RL, Hnkinson SE. Racial differences in premenopausal endogenous hormones. Cancer Epidemiol Biomarker Prev 2005; 14: 2147-2153.

51. Herman-Giddens ME, Slora EJ, Wasserman RC, Bourdony CJ, Bhapkar MV, Koch GG, Hasemeier CM. Secondary sexual characteristics and menses in young girls seen in office practice: a study from the pediatric research in office settings network. Pediatrics 1997; 99: 505-512.

52. Kato I, Toniolo P, Koenig KL, Shore RE, ZeleniuchJacquotte A, Akhmedkhanov A, Riboli E. Epidemiologic correlates with menstrual cycle length in middle aged women. Eur J Epid 1999; 15: 809-814.

53. Ariel I. A historical review of breast cancer treatment. In: Leslie W, Houston J (Eds). Breast Cancer: Controversies in Management. Futura Publishing Co, Armonk, NY; 1994.

54. Margolis ML, Christie JD, Silvestri GA, Kaiser L, Santiago S, Hansen-Flaschen J. Racial differences pertaining to a belief about lung cancer surgery: results of a multicenter survey. Ann Intern Med 2003; 139: 558-563.

55. Gukas ID. Does surgery induce angiogenesis in breast cancer? Supporting evidence from Africa. Int J Surg 2005; 3(4): 289.

56. Retsky M, Baum M, Demicheli R, Gukas I, Hrushesky W. Enhanced surgery-induced angiogenesis may partially explain the excess breast cancer mortality of blacks compared to whites. In press, Int J Surg, May 2007. 